\title{
Epidemiology of preinvasive lesions of the cervix and accuracy of its screening modalities in low resource settings
}

\author{
Rashi Rashi*, Shaheen, Sharma Rajyashri, Godha Zeepee
}

Department of Obstetrics and Gynaecology, JN Medical College, AMU, Aligarh, India

Received: 12 March 2016

Accepted: 15 April 2016

\author{
*Correspondence: \\ Dr. Rashi Rashi, \\ E-mail: rashisinha7777@gmail.com
}

Copyright: () the author(s), publisher and licensee Medip Academy. This is an open-access article distributed under the terms of the Creative Commons Attribution Non-Commercial License, which permits unrestricted non-commercial use, distribution, and reproduction in any medium, provided the original work is properly cited.

\begin{abstract}
Background: Cervical cancer is the leading cause of deaths of women due to malignancies in developing countries worldwide. Having a latency period of upto10 years, preinvasive lesions of cervix give us a wide margin for detection and treatment before it becomes cancerous. This is the aim of this study is to establish a pattern of prevalence of these preinvasive lesions and find out correlation with various epidemiological factors and establish best screening modality in low resource settings like ours.

Methods: The cases were studied in terms of their epidemiologic characteristics. The diagnostic accuracy of visual inspection with acetic acid (VIA) and cytology was assessed using colposcopy and biopsy as the gold standard, chisquare test applied and power of the screening test calculated.

Results: Abnormal cytology (47/226) was mostly found in age group 30-40 29/47 (61.7\%), were para 2 to $434 / 47$ $(72.3 \%)$, belonged to class IV-V socioeconomic class $28(59.6 \%)$, belonged to rural areas $32 / 47(68 \%)$ were illiterate $29 / 47(61.7 \%)$ were married at a young age 15-17 23/47(49\%) and were not using any contraception 22/47(46.8\%). The diagnostic accuracy of the screening tests that is VIA and cytology was tested against the gold standard test which was taken as colposcopy and biopsy in our study.

Conclusions: VIA is a screening modality suitable for low resource setting like ours along with cytology. It also offers see and treat option for women in rural areas who are usually lost to follow up.
\end{abstract}

Keywords: Cervical intraepithelial neoplasia, Screening, Epidemiology, Risk factors

\section{INTRODUCTION}

Cervical cancer is the leading cause of deaths of women due to malignancies in developing countries worldwide. ${ }^{1}$ Having a latency period of upto10 years, preinvasive lesions of cervix gives us a wide margin for detection and treatment before it becomes cancerous. ${ }^{2}$ It has been estimated that even after putting in all the resources it's not possible to screen one fourth of the population of women in India. ${ }^{3}$ This is the aim of this study to establish a pattern of prevalence of these preinvasive lesions and find out correlation with various epidemiological factors and establish best screening modality in low resource settings like ours.

\section{METHODS}

In this study, patients coming to the OPD of the Gynaecology Department, over a period of three years, (2009-2011) with various complaints like vaginal discharge and post coital bleeding etc. were subjected to en VIA examination (visual inspection with acetic acid), and cytology. Selected cases were subjected to colposcopy and biopsy, which is taken as gold standard in the study. The cases were studied in terms of their epidemiologic characteristics. The diagnostic accuracy of VIA and cytology was assessed using colposcopy and biopsy as the gold standard, chi-square test applied and power of the screening test was calculated.

Inclusion criterions were; sexually active women in reproductive age group, women having suspicious lesions 
and women having persistent discharge per vaginum. All patients who had had hysterectomy or were pregnant or had carcinoma cervix were excluded from the study.

\section{RESULTS}

226 cases were subjected to VIA examination, using freshly prepared $5 \%$ acetic acid. $105(46.5 \%)$ cases were VIA positive. Same no of cases were also subjected to cytological evaluation. Upon cytological evaluation, 21 (9.3\%) had a normal cytology, 158(69.9\%) were inflammatory, $3(1.3 \%)$ had ASCUS, $1(0.4 \%)$ had AGUS, $26(11.6 \%)$ had LSIL and koilocytic changes, $11(4.9 \%)$ had HSIL, and 6 cases $(2.6 \%)$ had squamous cell carcinoma.

Abnormal cytology (47/226) was mostly found in age group 30-40 29/47 (61.7\%), were para 2 to $434 / 47$ $(72.3 \%)$, belonged to class IV-V socioeconomic class $28(59.6 \%)$, belonged to rural areas 32/47(68\%) were illiterate $29 / 47(61.7 \%$ ) were married at a young age 15 -
17 23/47(49\%) and were not using any contraception $22 / 47(46.8 \%)$. The diagnostic accuracy of the screening tests that is VIA and cytology was tested against the gold standard test which was taken as colposcopy and biopsy in our study.

The sensitivity of VIA examination, taking colposcopy and biopsy as the gold standard was found out to be $83.01 \%$ and specificity $64.73 \%$. The positive predictive value was $67.64 \%$ and negative predictive value was $68.75 \%$. Upon application of chi-square test, the value was found out to be 37.2 and the p-value was $<0.001$, which was statistically significant.

The sensitivity of cytological examination, using colposcopy and biopsy as the gold standard, was $62.5 \%$ and specificity was $85 \%$.The $\mathrm{p}$-value was significant in this case too, $(<0.001)$.

Table 1: Association of abnormal cytology and abnormal VIA with high risk factors

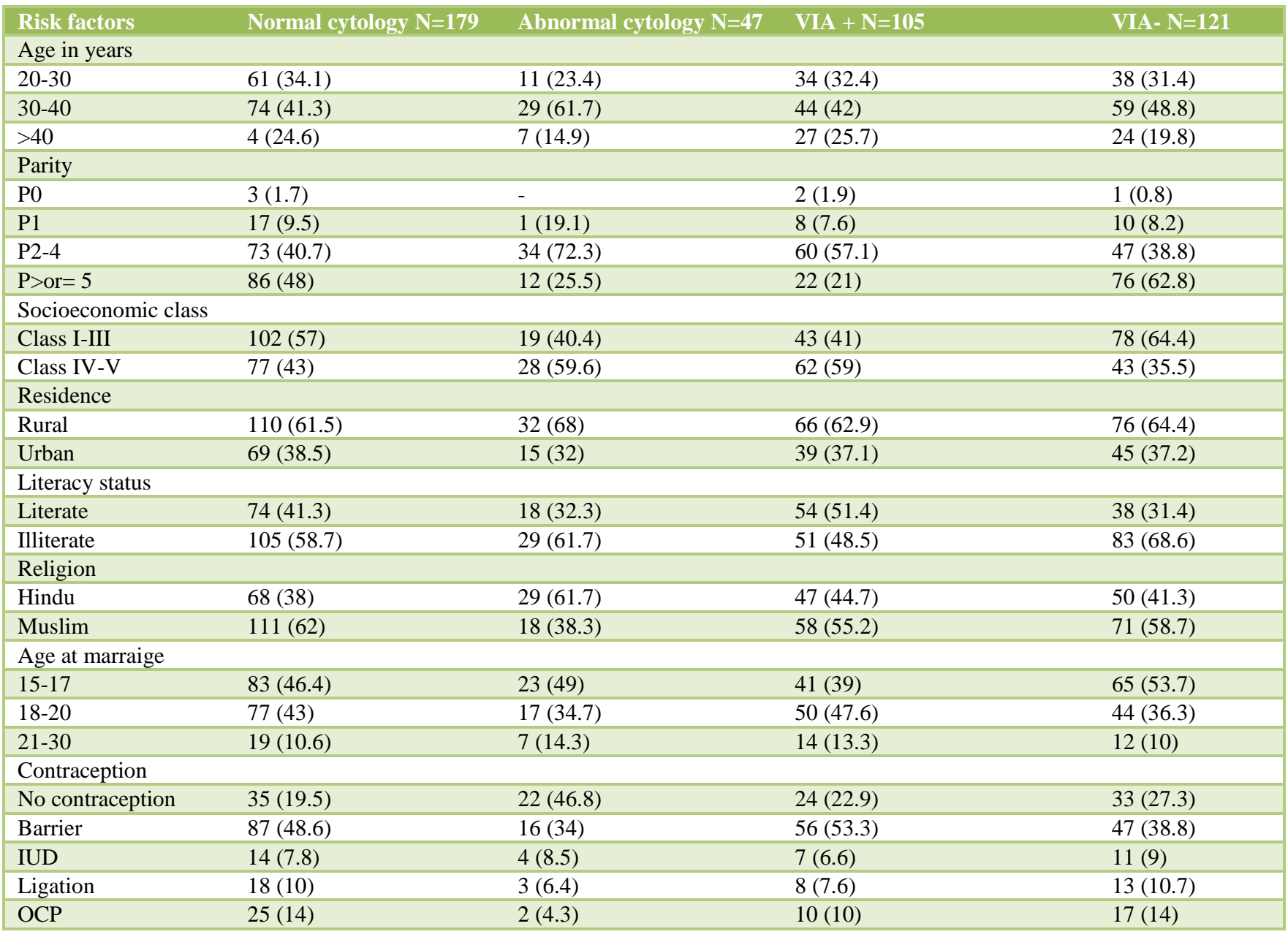




\section{DISCUSSION}

Abnormal cytology (47/226) was mostly found in age group 30-40 29/47 (61.7\%), were para 2 to $434 / 47$ $(72.3 \%)$, belonged to class IV-V socioeconomic class $28(59.6 \%)$, belonged to rural areas $32 / 47(68 \%)$ were illiterate $29 / 47(61.7 \%$ ) were married at a young age 15 17 23/47(49\%) and were not using any contraception $22 / 47(46.8 \%)$. The diagnostic accuracy of the screening tests that is, in our study most common presenting complaint was abnormal discharge, similar to a study conducted by Aggarwal et al $2006 .{ }^{4}$ VIA and cytology was tested against the gold standard test which was taken as colposcopy and biopsy in our study.

Appleby et al 2007, showed that use of oral contraceptive pills was associated with increased risk of cervical cancer, but in our study maximum cases were not using any contraception at all. ${ }^{5}$

Poor socioeconomic condition has been found to be associated with cancer as in poor living conditions by Harris et al 1998 and poor literacy rate as by Lindau et al 2002 . $^{6,7}$ A study of Stone et al 1995 showed early age of sexual debut and a large number of sexual partners were associated with increased cervical cancer. ${ }^{8}$

The sensitivity of cytological examination, using colposcopy and biopsy as the gold standard, was $62.5 \%$ and specificity was $62.5 \%$. Nanda et al 2000 showed a sensitivity of $68 \%$ and specificity of $75 \%$ of cytological examination. $^{9}$

The sensitivity of VIA examination, taking colposcopy and biopsy as the gold standard was found out to be $83.01 \%$ and specificity $64.73 \%$. The positive predictive value was $67.64 \%$ and negative predictive value was $68.75 \%$. Upon application of chi-square test the value was found out to be 37.2 and the p-value was $<0.001$, which was statistically significant. A study conducted by Ardhan et al 2011 showed sensitivity of $82.14 \%$, and specificity of $50 \% .^{10}$ The sensitivity was almost comparable our study.

\section{ACKNOWLEDGEMENTS}

We thank all the patients and the HOD of pathology department without them, this work would not have been possible.

Funding: No funding sources Conflict of interest: None declared

Ethical approval: Not required

\section{REFERENCES}

1. IARC Globocan, 2008. Available at http://www.iarc.fr/en/mediacentre/iarcnews/2010/glo bocan2008.php.Accessed on 10 February 2016.

2. OOrtmarssen GJV, Habbema JD. Epidemiological evidence for age- dependent regression of preinvasive cervical cancer. $\mathrm{Br}$ J Cancer.1991;64(3):559-65.

3. Aswathy S, Mariya AQ, Beteena K and Leelamoni K. Cervical cancer screening: Current knowledge and practice among women in rural population of kerala, India. Ind J Med Res.2012;136:205-10.

4. Aggarwal R, Gupta S, Nijhawan R, Suri V, Aur A, Bhasin V, Arora SK. Prevalence of high risk human papillomavirus infections in women with benign cervical cytology: A hospital based study from North India.Ind J cancer.2006;43(3):110-6.

5. Appleby $\mathrm{P}$, Beral V, Berrington GA, Colin D, Franceschi S, Goodhill A, Green J, Peto J, Plummer M, Sweetland S, Cervical cancer and hormonal contraceptives: collaborative re-analysis of individual data for 16,573 women with cervical cancer and 35,509 women without cervical cancer from 24 epidemiological studies. Lancet.2007;370 (9599):1609-21.

6. Harris V, Sandridge AL, Black RJ, Brewster DH, Gould A, Cancer registration statistics: Scotland, Edinburgh : ISD Scotland publications; 19861995:9-10.

7. Lindau ST, Tomori C, Lyons T, Langseth L, Bennet CL, Garcia P. The association of health literacy with cervical cancer prevention knowledge and health behaviours in a multiethnic cohort of women. AJOG.2002;186(5):938-43.

8. Stone KM, Zaidi A, Rosero - Bixby L, Oberle MW, Reynolds G, Larsen S, Nahmias J, Lee F, Shachter J, Guinan ME. Sexual behaviour, Sexually transmitted diseases and Risk of cervical cancer. Epidemiology. 1995;6:409-14.

9. Nanda K, McCrory DC, Myers ER, Bastian LA, Hasselblad V, Hickey JD, Matchar DB. Accuracy of Papanicolaou test in screening for and follow up of cervical cytologic abnormalities.Ann Intern Med.2000;132(10):810-9.

10. Ardahan M, Temel, Alya B. Visual inspection with acetic acid in cervical cancer screening.Cancer Nursing.2011;34(2):58-163.

Cite this article as: Rashi R, Shaheen, Sharma R, Zeepee G. Epidemiology of preinvasive lesions of the cervix and accuracy of its screening modalities in low resource settings. Int J Reprod Contracept Obstet Gynecol 2016;5:1582-4. 